\title{
A constituiçãa de sujeitos em redes de conversações
}

\author{
Elenice Soares \\ Willian Mella Girotto \\ Mára Lúcia Fernandes Carneiro \\ Instituto de Psicologia - UFRGS \\ elenicesoares2003@yahoo.com.br, williangirotto@gmail.com, mara.carneiro@frgs.br
}

\begin{abstract}
Resumo: O presente artigo apresenta os primeiros indicativos para uma proposta de metodologia de análise de redes de conversação. A pesquisa envolve a observação das interações e interlocuções que ocorrem em fóruns de discussão de cursos realizados a distância, com o apoio de um ambiente virtual de aprendizagem, buscando identificar inicialmente quais as características ou temas que apontam para a constituição de redes de conversação, a partir do conceito de conversa proposto por Humberto Maturana. A pesquisa pretende, a partir de seus resultados, indicar algumas orientações de atividades e procedimentos a serem adotados em cursos de formação de tutores e professores online.

Palavras Chaves: redes de conversação, educação a distância, ambientes virtuais de aprendizagem.
\end{abstract}

\begin{abstract}
This paper presents some issues concern to a methodology proposal to conversation networks analyses. This research deals with the distance education environments and discussion forum's observation, trying to identify some features that indicate conversation networks constitution, in Humberto Maturana's point of view. From the results, we intend to indicate activities and orientations that can be used in courses to prepare tutors and online teachers.

Keywords: network conversation, distance education, virtual learning environments
\end{abstract}

\section{INTRODUÇÃO}

A integração entre tecnologia e educação, através da utilização de ambientes virtuais de aprendizagem (AVA), permite outras formas de interagir, ampliando o acesso à educação, já que não é mais necessário que professor e aluno estejam no mesmo ambiente físico. Isso possibilita outras formas de relacionamento, seja alunoaluno, seja aluno-professor-tutor. Esse estudo surgiu no contexto de formação a distância, em que a atuação de professores e tutores possibilitaria a real constituição de redes de conversação, ampliando a troca de experiências, dúvidas e solução de problemas. Sendo assim, a rede seria um facilitador do processo de formação. Isso foi possível a partir da pesquisa realizada por Carneiro (2003) que trouxe subsídios para repensarmos não só a comunicação em rede e seus fluxos, mas também como os acoplamentos tecnológicos atravessam os processos de subjetivação que constituem os sujeitos imersos em ambientes virtuais.

Com o crescente desenvolvimento da área de educação a distância (EAD) tornou-se importante entender como ocorrem os fluxos comunicacionais, os acoplamentos tecnológicos e os processos de subjetivação que surgem das relações estabelecidas em AVA. A observação dos processos comunicativos que se estabelecem durante cursos a distância apoiados intensivamente no uso das tecnologias de informação e comunicação gerou nosso problema de estudo: 
Como se constituem as redes de conversação em sujeitos participantes através das coordenações de coordenações de ações que ocorrem nos fluxos comunicacionais ${ }^{l}$ em cursos de graduação oferecidos na modalidade a distância?

O objetivo geral da pesquisa é analisar os fluxos comunicacionais e os acoplamentos tecnológicos que ocorrem na formação docente e que dão suporte à constituição do professor online. Os objetivos específicos são: a) identificar os recursos tecnológicos que apóiam e promovem a constituição de fluxos comunicacionais em cursos a distância; b) analisar os fluxos comunicacionais que surgem nas interações apoiadas por recursos de comunicação como os fóruns e bate-papos, em um ambiente virtual de aprendizagem; c) analisar as coordenações das coordenações de ações na constituição do sujeito como participante de um grupo; d) descrever os acoplamentos tecnológicos presentes na constituição de sujeitos interagindo em ambientes digitais e a distância.

\section{A BIOLOGIA DO CONHECER E AS REDES DE CONVERSAÇÃO}

\section{O acoplamento estrutural e tecnológico possíveis}

Para a realização de nosso estudo, usaremos algumas concepções da Biologia do Conhecer, nome dado ao conjunto teórico de Humberto Maturana. Para entendermos o que significa o conversar para tal autor, é preciso compreender primeiramente a noção de emocionar e de linguajar. O emocionar é qualquer operar em um domínio, que leva um terceiro a desencadear novas ações a partir disso. Para que ocorra uma conversação, é necessário emocionar o outro, fazendo com que ele desencadeie novas ações. Estas, por sua vez, despertarão o emocionar em outros participantes, disparando novas ações de sua parte. A emoção o faz partir de um domínio de ações para outro, de um processo para outro, faz sair do que ele estaria habituado a fazer, direcionando para um novo domínio de ações.

Já o linguajar é um neologismo criado por Maturana (2001) para se referir ao ato de estar na linguagem sem que seja necessário associar esse fato à fala, como aconteceria se a palavra falar fosse utilizada no lugar da palavra linguajar.

... as palavras constituem operações no domínio de existência, como seres vivos, dos que participam na linguagem, de tal modo que o fluir de suas mudanças corporais, posturas e emoções tem a ver com o conteúdo de seu linguajar. (MATURANA, 2001 p.168).

Não há conversa quando há somente uma pessoa emitindo símbolos sem que a outra compreenda o significado desses símbolos. Os símbolos isolados, por si só, não constituem a linguagem. Eles precisam ser consensuais entre os participantes para que ocorra a conversa. Ou seja, é necessário que os observadores - nós, seres humanos que vivemos na linguagem - associem significados para estes símbolos. Tal significado somente é estabelecido numa relação de coordenações de condutas consensuais. A linguagem não tem lugar no corpo físico dos participantes, mas sim no espaço de coordenações de condutas consensuais. Tal espaço somente é estabelecido quando há consenso entre os participantes.

Para Maturana (1998), o conversar deriva do latim cum que significa com e versare, dar voltas com. Segundo Maturana (1998, pg. 84), o conversar é "o fluir entrelaçado de linguajar e emocionar". No uso da linguagem para nos comunicarmos 
com outro indivíduo, nossas emoções podem mudar, fazendo-nos partir de um domínio de ações para outro. Ao mesmo tempo, nosso emocionar, no fluir em um domínio de ações, modifica o curso de nosso linguajar.

Outro conceito importante é a o de acoplamento estrutural (Maturana, 2001). Ao ser perturbado em seu viver, um indivíduo sai de seu estado e têm de se adaptar a essa nova situação, modificando sua estrutura. Ao mesmo tempo em que ele faz isso, essas alterações afetarão o meio. Temos, então, a noção de um organismo que se desenvolve acoplado ao seu meio, ao mesmo tempo em que ele sofre alterações. O acoplamento reformula o viver, nos modificando fisicamente e/ou psicologicamente. Ao contrário da visão cognitivista que pressupunha um meio imutável e um organismo se adaptando a ele, o acoplamento estrutural se refere à dinâmica da estrutura do organismo que sempre se desenvolve acoplado ao meio, ao mesmo tempo em que o meio sofre alterações na interação com esse.

Cada ambiente virtual possui recursos diferenciados para a estruturação de curso a distância, considerando a disponibilização de espaços de interação e comunicação, além daqueles para publicação das orientações e materiais do professor.

Os ambientes virtuais de aprendizagem são, na realidade, programas que reúnem uma série de recursos para apoiar a comunicação e a cooperação. Estes ambientes podem constituir domínios comunicacionais diferenciados, em função do uso que fizermos destes recursos. (Carneiro, 2003 p.32-33).

Assim, um aluno, tutor ou professor iniciante no uso dos recursos de um ambiente virtual de aprendizagem (AVA), precisa inicialmente se apropriar e adaptar ao uso dessa outra sala de aula, agora virtual, o que se aproxima da idéia de acoplamento proposta por Maturana. A este tipo de acoplamento, que envolve o uso de recursos informatizados, adotamos a denominação de "acoplamento tecnológico" (Carneiro, 2003).

\section{As redes de conversação e a metáfora da orquestra comunicacional}

Winkin (1998) apresenta a analogia da orquestra, que leva em conta a participação de cada indivíduo na comunicação, indicando que o processo comunicacional envolve trocas coordenadas e multidirecionais. Esta visão contrapõe-se aos modelos tradicionais da teoria da comunicação, descritas por Reedy (1979) através da análise da metáfora do tubo, onde a comunicação é pressuposta unidirecional, partindo de um emissor para um receptor. A "nova" visão da comunicação tem como objetivo mostrar "como podemos dizer que cada indivíduo participa da comunicação, mais do que é a sua origem ou ponto de chegada". (Winkin, 1998, p.33).

Utilizando a analogia da orquestra podemos ter uma imagem dessa concepção de comunicação. Somos como membros de uma orquestra, como os músicos que fazem parte dela. Cada um toca adaptando-se ao outro. Se utilizarmos as concepções de Maturana, podemos pensar que há um acoplamento entre os músicos da orquestra para que seja possível tocar uma música. Cada músico "perturba" o outro com seu som e com essa perturbação surge um emocionar que fará com que os músicos comecem a se acoplar, uns se moldando aos sons dos outros até que seja possível produzir um som organizado, uma música. Essa música seria a comunicação, o conversar para Maturana.

A analogia da orquestra nos foi muito útil para pensarmos e analisarmos as redes de comunicação. Assim como na orquestra, a "música tocada" pela rede vai sendo composta aos poucos, com a agregação de novos membros pouco a pouco conforme vai 
ocorrendo o acoplamento entre os participantes. Cada integrante tocando seu instrumento, que seria sua fala expressa através de seus textos e mensagens publicados no ambiente virtual, vai se acoplando aos outros para juntos construírem a conversa. Quando percebermos essa "música" em um dos fóruns, poderemos inferir que ali está ocorrendo um efetivo conversar e, portanto, que pode ter se formado uma rede de conversação.

\section{OBSERVANDO E PESQUISANDO}

Consideramos a presente pesquisa de cunho qualitativo estruturada como um estudo de caso, visto que o estudo de caso permite abordar a complexidade de um fenômeno num contexto real no qual a pesquisa ocorre e permite descrever dessa maneira não só a intervenção de pesquisa, mas as situações derivadas dela (Stake, 1999).

\section{O campo de pesquisa e os espaços de observação}

Ao longo de 2007 e 2008, foram realizados sete cursos de capacitação em EAD, para professores, tutores a distância e tutores presenciais que viriam a atuar nos cursos de licenciatura a distância, oferecidos pela Rede Gaúcha de Ensino Superior a Distância $\left(\right.$ REGESD $\left.^{2}\right)$. Dentro desse contexto, foram ministrados sete cursos de formação, que contaram com um total de aproximadamente 485 alunos. Desse total de alunos, 90 deles foram escolhidos para serem acompanhados. Após a primeira etapa da pesquisa, onde realizamos uma avaliação preliminar e levantamos alguns critérios de avaliação, buscamos validar o procedimento observando um curso regular de graduação a distância, no qual a professora pesquisadora também era ministrante. Assim, foi selecionado um grupo de 30 alunos, vinculados a um dos pólos presenciais do curso de graduação tecnológica em Planejamento e Gestão do desenvolvimento Rural (PLAGEDER)

O ambiente virtual de aprendizagem utilizado tanto pelos cursos da REGESD, quanto do PLAGEDER foi o Moodle. Dentro desse ambiente, a ferramenta Fórum foi selecionada para a observação dos fluxos comunicacionais que ali se estabeleciam e os possíveis acoplamentos tecnológicos. Este recurso de comunicação foi escolhido para ser observado por ser o local efetivamente considerado pelos alunos como a "sala de aula" e onde eram proporcionados espaços para interação reflexiva. No projeto de pesquisa original previu-se inicialmente a seleção e entrevista de participantes do curso para definição da amostra a ser observada. Os critérios para a seleção desses participantes eram não ter experiência prévia como professor online (ou seja, nunca terem atuado como docente em cursos a distância mediados pela Internet) e pertencerem a uma das áreas do conhecimento representativos das nove áreas dos cursos de licenciatura que foram oferecidos pelo Projeto Pró-Licenciaturas através da REGESD.

No entanto, a pesquisa teve início após a realização dos cursos de capacitação, e não foi possível realizar as entrevistas. Sendo assim, o que foi possível de ser realizado foram alguns mapeamentos dos perfis dos participantes com base no recurso Perfil do ambiente virtual MOODLE e em suas apresentações nos fóruns observados. Dessa forma, identificamos sujeitos que tiveram uma participação ativa nos fóruns, postando muitas mensagens e que em seu discurso apontavam que essa era a sua primeira participação em uma ferramenta EAD (aproximadamente dezesseis participantes). Outros sujeitos observadores eram aqueles que participaram ativamente e destacaram que isso ocorreu por conta de experiências anteriores (aproximadamente dezoito participantes). Como em qualquer espaço de sala de aula, também foram identificados 
participantes que somente respondiam às atividades propostas, isto é, interagindo quando questionados a interagir, postando poucas mensagens (aproximadamente trinta participantes). Alguns sujeitos participaram mais dos espaços informais do que do espaço de ensino e aprendizagem (aproximadamente sete participantes), enquanto outros responderam a poucas mensagens (aproximadamente sete participantes), ou não postaram nenhuma mensagem (aproximadamente doze participantes).

No PLAGEDER os participantes foram escolhidos por participarem de um pólo em que o tutor tinha experiência de uma edição anterior deste curso e porque o perfil da turma era bem variado quanto à idade e aos conhecimentos de internet e informática. Estes dados foram obtidos a partir das respostas fornecidas pelos alunos em um questionário socioeconômico que foi preenchido na inscrição do vestibular. Deste questionário tivemos acesso aos dados como turma e não dados individuais.

\section{Pensando em ferramentas para identificar a rede de conversação}

Para estudar o processo de formação das redes, buscamos inicialmente o auxílio da análise de conteúdo, tentando encontrar e construir categorias de palavras que indicariam a formação de uma rede de conversação. Segundo Bardin (1977), a categorização é a divisão dos elementos em classes que reúnam características em comum. Após essa divisão em grupos, é feito uma seleção segundo critérios préestabelecidos. A presença das categorias em um fórum nos indicaria elementos de que os sujeitos estavam conversando.

A aplicação do método nos diversos fóruns observados apontou para algumas categorias. No entanto, uma das maiores dificuldades encontradas foi que muitas vezes tornava-se impossível enquadrar uma palavra ou grupo de palavras de palavras em uma única categoria. Era preciso analisar o contexto em que a palavra aparecia e a que ela se referia. Foi a partir das contribuições de Wikin (1998) que chegamos à conclusão de que as mensagens e seus trechos precisavam ser analisados em seu contexto e em seu conteúdo, e, portanto, não havia como criar categorias gerais. Isso nos apontou também para a necessidade de encontrar outra maneira de analisar o processo de constituição das redes que permitisse identificar movimentos e transformações.

Maçada (2001) faz um paralelo entre as situações ocorrentes em um ambiente virtual de aprendizagem (AVA) e a Teoria do Caos (Prigogine, 1996; Capra, 1996), afirmando que ambas são semelhantes. É preciso compreender o caos, não mais como ausência total de ordem, mas sim como alguma falta de ordem. A autora afirma que como em um AVA existem situações e oscilações da ordem, tal qual os sistemas da teoria do caos, o que nos permite pensá-lo como um sistema dinâmico. Os sistemas dinâmicos, segundo Prigogine (1996), são aqueles que são compreendidos fora da visão antropocêntrica de natureza, e onde é possível encontrar a ordem na desordem - teoria do caos. Dentro do funcionamento desse sistema dinâmico, há o surgimento de atratores, que nada mais são que "pontos de convergência que emergem nos sistemas e funcionam como uma espécie de imã, atraindo e organizando o sistema em torno de um ponto". (Capra, 1996). Os atratores podem ser compreendidos como operadores que exprimem uma maneira de agir num determinado domínio, transformando o mesmo. Além disso, eles emergiriam a partir do funcionamento do sistema, agregando este e indicando uma organização através da identificação de padrões no sistema. Segundo Maçada (2001, p. 55), "os atratores possuem uma certa regularidade dentro do irregular, uma desorganização organizada [sendo assim] podemos [pensar] que há previsibilidade dentro do caos em função de uma certa pertinência e constância dessa irregularidade". 
Poderíamos entender os atratores como perturbações nos sujeitos participantes da rede de conversação. Afetados por essas perturbações, eles começariam a interagir uns com os outros, ou seja, partiriam de um domínio de ações para outro. Partindo da concepção de que o emocionar é o que nos faz partir de um domínio para outro, os atratores seriam perturbações que auxiliariam nesse processo.

Procurando observar o processo da conversação, podemos perceber que algumas interações ganham destaque e que direcionam como vão se estabelecendo as relações no ambiente virtual de aprendizagem. Nossa intenção é utilizar os atratores que emergem nos fóruns observados como recursos para apoiar a nossa análise. Optamos por utilizador os atratores, já que eles não só auxiliam a compreensão da constituição das redes, através da identificação de como está ocorrendo o acoplamento entre os participantes, como também possibilita identificar quais padrões se repetem. Além disso, eles nos trariam a identificação das formas mais apropriadas de estruturar cursos a distância e orientar a atuação do tutor ou professor para uma mediação mais eficiente dentro do AVA.

\section{APONTANDO ALGUNS NOVOS CAMINHOS}

\section{Acoplamento tecnológico podendo gerar uma rede de conversação}

Um de nossos apontamentos foi que o sujeito ao se acoplar com o ambiente virtual produz o acoplamento tecnológico que, por sua vez, pode indicar a existência de uma rede de conversação. $O$ usuário somente postou mensagens se estivesse instrumentalizado para operar no ambiente virtual, isto é, acoplado ao ambiente. Portanto, a rede de conversação é um indicador de que houve acoplamento tecnológico. Dessa forma, o postar mensagens aparece como um indicador do acoplamento tecnológico.

\section{As redes de conversação}

Foi observada nos tópicos dentro das mensagens, a existência de um comentário disparador que inicia o processo da rede de conversação. Geralmente, ele é um imperativo ou um questionamento que possibilita o surgimento de novas mensagens a partir disso. Após a mensagem disparadora ser emitida, começa uma seqüência de respostas a ela. Com o emocionar, os sujeitos sentem-se convidados a responder a mensagem disparadora, introduzindo novas questões, gerando novas mensagens disparadoras. Dessa forma, os discursos vão se entrelaçando com a mensagem inicial e com as novas mensagens que se originaram delas, constituindo uma rede de conversação de fato. Sendo assim, podemos observar que a conversação não ocorre de forma linear, mas sim em forma de rede. Existem mensagens que demonstram uma conexão com as demais que foram emitidas até o momento, enquanto outras demonstram uma ligação exclusiva com a mensagem que abriu o tópico.

\section{Alguns atratores encontrados}

Até o presente momento da pesquisa foram identificados alguns atratores que afetariam a constituição das conversações nos AVA. Entre eles, podemos destacar os seguintes:

\section{Contexto acadêmico}

A interação que ocorre nos espaços de formação do ambiente virtual de aprendizagem é diferente daquela que ocorre nos ambientes informais. Isso ocorre pelo 
fato desse espaço de formação ser um ambiente acadêmico. É preciso compreender esse espaço como um lugar que ao ensinar e avaliar, pode causar nos alunos certa intimidação. $\mathrm{O}$ aluno é sujeito à avaliação por parte do professor e a julgamentos por parte dos colegas. Há um esforço para participar da melhor maneira possível, fazendo com que o aluno tenha cuidados com a correção gramatical, com a linguagem mais formal, com o uso correto dos conceitos, tentativa de escrever adequadamente, entre outros. A figura 1 mostra um extrato de conversa que exemplifica esse atrator. $\mathrm{O}$ grifo no texto indica a expressão associada.

Re: Você sabe o que é Educação a Distância? por R. M. G. M. - terça, 18 agosto 2009,10:05
Conforme o que li no matenal oferecido, entendi em deteminado momento que educação a distâncią
venha ser uma modalidade de ensino onde o aluno e o profo não estão sempre juntos de corpo presente
dentro de uma sala de aula, mas ao mesmo tempo podem estar interligados virtualmente, postando seus
conhecimentos e tirando dúvidas.Utilizando-se dos recursos : intemet, correio, rádio, tw, vídeo, telefone
fax, CD-Rom, do tipo apostilas para concursos. E, assim as pesquisas vão se aprofundando, a interação se
abrange cada vez mais e o aluno adquire maior conhecimento a distância.

Figura 1 - Exemplo de atrator Contexto acadêmico

FONTE: Extraído do Fórum Você sabe o que é Educação a Distância? Tópico "Você sabe o que é Educação a Distância” da disciplina "Introdução a Educação a Distância”.

\section{Auto-organização do grupo}

Após um aluno postar uma mensagem em que aponta suas dificuldades com o uso do ambiente e sua desestimulação com o curso, o grupo se organiza para dar suporte a esse aluno. A partir dessa mensagem, em que aparecem os sentimentos em relação ao curso, podemos observar um emocionar que mobiliza o grupo, fazendo com que este desencadeie uma série de mensagens buscando dispor ajuda para o colega em dificuldade. A figura 2 traz um extrato do fórum, onde foi assinalada a expressão que permitiu identificá-lo.

Re: Você sabe o que é Educação a Distância?por R. M. G. M. - terça, 18 agosto 2009, 10:05

M!! Obrigada pela coragem de começar nesta edição, se assim posso dizer, não tive oportunidade dê acesso anteniomente, mais ainda que conjuntamente com você e os demais formular o entendimenté correto da questão pautada.

Figura 2 - Exemplo de atrator Auto-organização do grupo

FONTE: Extraído do Fórum Você sabe o que é Educação a Distância? Tópico "Você sabe o que é Educação a Distância" da disciplina "Introdução a Educação a Distância".

\section{A construção compartilhada do conhecimento}

A partir do material disponibilizado pelo professor para os fins de ensino, podemos ter alunos interessados em compartilhar conhecimento e trocar experiências com seus colegas. 


\section{Re: Você sabe o que é Educação a Distância? por R. M. G. M. - terça, 18 agosto 2009, 10:05 Se entendi. não tenho certeza. considero características relevantes: a flexibilidade de horáno para estudo depende de organização e planejamento); a redução de custos com deslocamento( tempo e financeiro) iniciativa( depende de muito esforço do aluno, ele deve correr atrás); inovações( cada vez mais o alun rai aprimorando suas fortes de pesquisas); segurança( 0 aluno e o professor sai de casa, só o inevitável e não deixa de aprender porque sua sala de aula está ali, assim tem menos risco quarto a violência en geral); atualização( 0 aluno vai se enquadrarnos moldes atuais, a informatização). 0 que vocês tem a me dizer sobre isso? Pois tenho muita dificuldade. preciso da opinião de todos.}

Figura 3 - Exemplo de atrator Construção compartilhada do conhecimento FONTE: Extraído do Fórum Você sabe o que é Educação a Distância? Tópico "Você sabe o que é Educação a Distância" da disciplina "Introdução a Educação a Distância".

Através das discussões, os alunos se utilizam de elementos que apareceram anteriormente nas postagens dos colegas para refletir e fazer novas construções, possibilitando a formação de uma rede de conversação. Diferentemente do aluno que somente se preocupa em responder o que é proposto, gerando uma interação do gênero pergunta-resposta. Não se consegue observar o emocionar nesse tipo de interação, logo, não se estabeleceram os parâmetros esperados para que acontecesse uma conversação. A figura 3 mostra um exemplo deste atrator.

\section{O papel do tutor}

A atuação do tutor é imprescindível à forma como a rede de conversação se estrutura. Muitas vezes, a rede de conversação se expande em assuntos secundários, ou ela não se estabelece. $\mathrm{O}$ atuar do tutor indica a necessidade de um direcionamento da conversação para que ela não perca seu objetivo pedagógico. Sendo assim, o tutor pode intervir no domínio virtual, através da coordenação de coordenação de ações, retomando o que foi dito pelos participantes, a fim de suscitar novas questões. A partir disso, a ação do tutor perturba os participantes do ambiente virtual de aprendizagem através do emocionar, fazendo os alunos retornarem e retomarem o que já disseram, ou ainda responder o que o tutor acabou de propor. Dessa forma, eles começam a emitir novas repostas às questões propostas, fazendo uso das palavras, isto é, do linguajar. Portanto, podemos observar que a atuação do tutor contribui para o desenvolvimento do conversar entre os participantes. É possível de entender o tutor como o regente da orquestra, que ao indicar caminhos para as discussões, fazendo com que os músicos, sujeitos integrantes do ambiente virtual, vão produzindo a música, a rede de conversação em conjunto. 


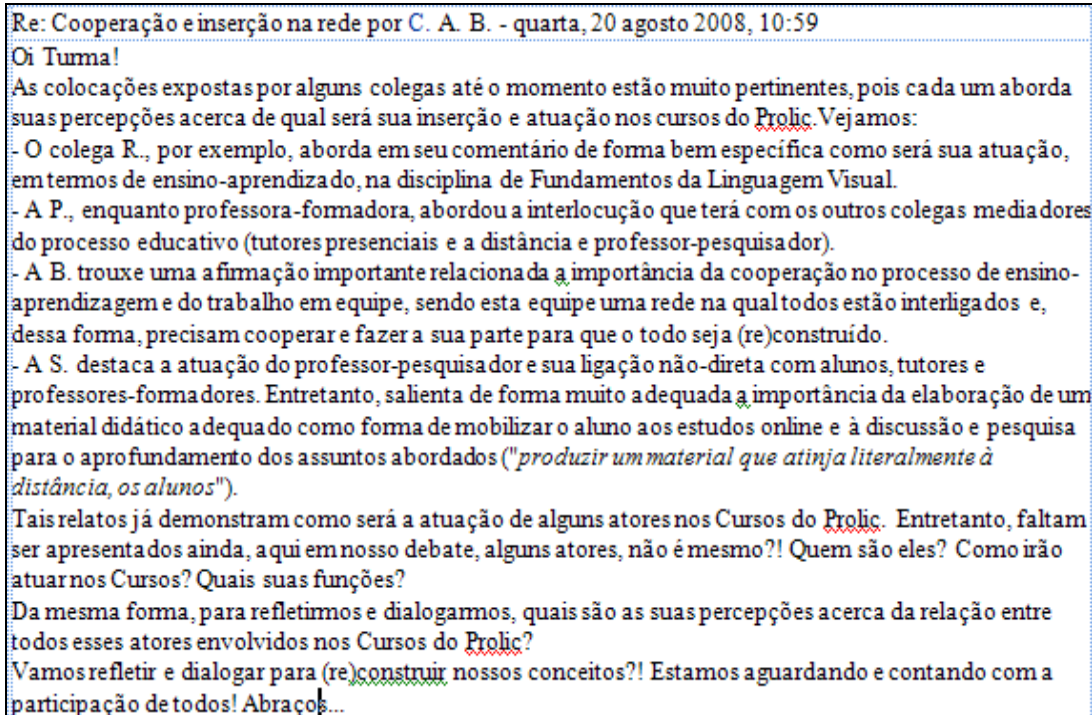

Figura 4 - Exemplo de atrator Papel do tutor

FONTE: Extraído do Fórum "Pró-Licenciatura e a REGESD",

Tópico "Cooperação e inserção na rede" do curso "Fundamentos da EAD".

É importante ressaltar que ainda que o tutor seja o maestro da orquestra, são os músicos, participantes do AVA, que vão produzir a música, a rede de conversação.

A maneira como o tutor interage com os alunos pode organizar as interações de diferentes maneiras. Um tutor sempre presente e que responde prontamente aos questionamentos pode fazer com que os alunos sintam-se mais motivados a freqüentar o AVA. Outra maneira que podemos pensar é como o tutor propõe as questões no fórum, se ele faz isso de maneira que possibilite que seja respondida de várias formas, uma questão aberta, ou se ele propõe questões mais pontuais, que terão respostas mais objetivas e menos probabilidade de gerar ou continuar uma discussão entre os integrantes do grupo. Em ambas as situações, podemos observar o emocionar por parte do tutor que auxilia na formação da rede de conversação. A figura 4 apresenta $o$ exemplo de uma mensagem ilustrando o atrator vinculado à atuação do tutor.

\section{CONSIDERAÇÕES FINAIS}

$\mathrm{Na}$ busca pelo entendimento de como as redes de conversação se constituíam e de como poderíamos observar as interações, pensamos inicialmente em procurar categorias de palavras que se repetissem e que de alguma forma poderiam estar organizando as interações. Percebemos que categorias de palavras nos dariam apenas uma visão do que ocorria no momento, como se fosse uma fotografia da interação, as categorias eram estáticas e estavam muito ligadas ao conteúdo da mensagem. Então, visando entender o processo buscamos o modelo comunicação, enquanto orquestra, proposto por Winkin (1998), que tem coerência com o referencial teórico da Biologia do Conhecer de Maturana. Além disso, a concepção dos atratores, descrita por Maçada (2001), nos auxiliou a entender o processo por não serem estáticos, e estarem constantemente se modificando, produzindo novos atratores, e outras formas de organização do sistema. 
Portanto, a teoria dos atratores nos auxilia na análise da rede de conversação até o momento. Com a identificação dos atratores encontrados até o momento, será possível não só pensar em novas formas de atuação nos AVA, proporcionando uma ampliação na troca entre os diversos membros do processo de ensino-aprendizagem, como também estruturar cursos a distância e orientar a atuação do professor ou tutor para uma mediação mais eficiente dentro do AVA. Tais aspectos possibilitariam uma maior qualificação no processo de formação na EAD. Além disso, pretendemos validar os atratores encontrados através da observação da nova turma do PLAGEDER. Buscaremos, também, identificar outros possíveis atratores que emergirão na rede de conversação.

\section{NOTAS}

${ }^{1}$ Fluxos comunicacionais aqui entendidos como no sentido adotado por Maturana, que entende a comunicação como o "desencadeamento mútuo de comportamentos coordenados que se dá entre os membros de uma unidade social". (2001, p. 214).

${ }^{2}$ REGESD - http://www.regesd.tche.br

\section{REFERÊNCIAS}

BARDIN, Laurence. Análise de conteúdo. Lisboa: Edições, 1977.

CAPRA, Fritjof. A teia da vida: uma nova compreensão científica dos sistemas vivos. São Paulo: Cultrix, 1996.

CARNEIRO, M.L.C. O acoplamento tecnológico e a comunicação em rede: inventando outros domínios de aprendizagem. Porto Alegre: Programa de PósGraduação em Informática na Educação/ UFRGS, 2003. 162p. Tese de Doutorado.

MAÇADA, D. L. Rede virtual de aprendizagem - interação em uma ecologia digital. Porto Alegre: Pós-Graduação em Informática na Educação/UFRGS, 2001. 153p. Tese de Doutorado.

MAGRO, Cristina. A biologia do conhecer: suas origens e implicações. In: Maturana, H. A ontologia da realidade. Belo Horizonte: Editora da UFMG, 2001. p. 31-52.

MATURANA, Humberto. Da biologia a psicologia. Porto Alegre: Artes Médicas, 1998. REEDY, M. The Conduit Metaphor: a case of frame conflict in our language about language. In: ORTONY, A. Metaphor and thought. Londres, Cambridge University Press, 1979. p. 164-201.

STAKE, Robert. E. The art of Case Study Research. London: Sage Publication, 1999. WINKIN, Yves. A nova comunicação: da teoria ao trabalho de campo. Campinas (SP): Papirus, 1998. 